\title{
Age-related improvement in complex language comprehension: Results of a cross-sectional study with 361 children aged 5 to 15
}

Citation for published version (APA):

Wassenberg, R., Hurks, P. P. M., Hendriksen, J. G. M., Feron, F. J. M., Meijs, C. J. C., Vles, J. S. H., \& Jolles, J. (2008). Age-related improvement in complex language comprehension: Results of a crosssectional study with 361 children aged 5 to 15. Journal of Clinical and Experimental Neuropsychology, 30(4), 435-448. https://doi.org/10.1080/13803390701523091

Document status and date:

Published: 01/01/2008

DOI:

10.1080/13803390701523091

Document Version:

Publisher's PDF, also known as Version of record

Please check the document version of this publication:

- A submitted manuscript is the version of the article upon submission and before peer-review. There can be important differences between the submitted version and the official published version of record.

People interested in the research are advised to contact the author for the final version of the publication, or visit the DOI to the publisher's website.

- The final author version and the galley proof are versions of the publication after peer review.

- The final published version features the final layout of the paper including the volume, issue and page numbers.

Link to publication

\footnotetext{
General rights rights.

- You may freely distribute the URL identifying the publication in the public portal. please follow below link for the End User Agreement:

www.umlib.nl/taverne-license

Take down policy

If you believe that this document breaches copyright please contact us at:

repository@maastrichtuniversity.nl

providing details and we will investigate your claim.
}

Copyright and moral rights for the publications made accessible in the public portal are retained by the authors and/or other copyright owners and it is a condition of accessing publications that users recognise and abide by the legal requirements associated with these

- Users may download and print one copy of any publication from the public portal for the purpose of private study or research.

- You may not further distribute the material or use it for any profit-making activity or commercial gain

If the publication is distributed under the terms of Article 25fa of the Dutch Copyright Act, indicated by the "Taverne" license above, 


\title{
Age-related improvement in complex language comprehension: Results of a cross-sectional study with 361 children aged 5 to 15
}

\author{
Renske Wassenberg, 1 Petra P. M. Hurks, ${ }^{1,2}$ Jos G. M. Hendriksen, ${ }^{1,3}$ \\ Frans J. M. Feron, ${ }^{4}$ Celeste J. C. Meijs, ${ }^{1}$ Johan S. H. Vles, ${ }^{5}$ and Jelle Jolles ${ }^{1}$ \\ ${ }^{1}$ Department of Psychiatry and Neuropsychology, Maastricht University, Maastricht, \\ The Netherlands \\ ${ }^{2}$ Department of Psychology, Maastricht University, Maastricht, The Netherlands \\ ${ }^{3}$ Childhood Rehabilitation Centre Franciscusoord, Valkenburg, The Netherlands \\ ${ }^{4}$ Youth Health Care Division of the Regional Public Health Institute, Maastricht, \\ The Netherlands \\ ${ }^{5}$ Department of Neurology, Maastricht University Hospital, Maastricht, The Netherlands
}

\begin{abstract}
We investigated age-related improvement in speed and accuracy of complex language comprehension with 361 children attending kindergarten and the 2nd, 4th, 6th, 7th, and 8th grades. Language comprehension was measured using both the neuropsychological procedure proposed by Luria $(1966,1980)$ and an adapted version of the Token Test. Levels of short-term memory and verbal intelligence were controlled for in the evaluation of language comprehension. The findings show that the accuracy of language comprehension continued to develop until the 6th grade, whereas the speed of language comprehension continued to improve up until the 7th grade. We thus conclude that the complex language comprehension of children is not fully developed until early adolescence. We further contend that the speed of complex language comprehension appears to be more sensitive than accuracy with respect to measuring developmental differences.
\end{abstract}

Language comprehension, production, and use are fundamental to social and academic success (Bashir \& Scavuzzo, 1992; Cook, Murdoch, Cahill, $\&$ Whelan, 2004). Although normal language development in children up to the age of five has been described extensively (Bates, Thal, Finlay, \& Clancy, 2003), little is known about the capacity of older children to understand complex language. Recent brain research has shown that certain regions of the human brain, especially parts of the prefrontal cortex, do not fully mature until early adulthood (De Bellis et al., 2001; Gogtay et al., 2004; Klingberg, Vaidya, Gabrieli, Moseley, \&
Hedehus, 1999). Because of this, complex cognitive functions also continue to develop into adolescence or early adulthood (P. Anderson, 2002; V. Anderson, Anderson, Northam, Jacobs, \& Catroppa, 2001; Casey, Tottenham, Liston, \& Durston, 2005; Eslinger, Flaherty-Craig, \& Benton, 2004; Fuster, 2002; Paus, 2005; Steinberg, 2005). The comprehension of complex language may be one of the cognitive functions that continue to develop beyond childhood and into adolescence given that it is (a) assumed to be essential for purposeful behavior, and (b) dependent on the maturation of the prefrontal cortex (Johnson \&

We are grateful to the schools, parents, and, most of all, children who participated in this study. In addition, we would like to thank the graduate students who were responsible for collecting the data: Marieke Van Gompel, Floortje Smeets, Martine Smeets, Leonie Steenis, Daphne Teerling, and Priscilla Theunissen. Finally, we would like to thank Peter Coopmans for his useful comments on an earlier version of this manuscript.

Address correspondence to Renske Wassenberg, Department of Psychiatry and Neuropsychology, Maastricht University, P.O. Box 616,6200 MD Maastricht, The Netherlands (E-mail: r.wassenberg@np.unimaas.nl). 
Munakata, 2005; Lezak, Howieson, \& Loring, 2004; Luria, 1966, 1980; Nigg, 2000; Stuss, 1992). If language comprehension does continue to develop into adolescence, large implications with respect to the practice of education can be expected. The efficiency of information transfer can then be expected to be dependent upon the extent to which the child can understand the intention of the teacher. Given this possibility, the present study investigated the degree to which 5- to 15-year-old children can comprehend complex sentences.

In clinical practice, three tests are often used to measure the accuracy of complex language comprehension in children. The first is the Reynell Test for Language Comprehension of the Reynell Developmental Comprehension Scales (Edwards et al., 1997). This test is available in Dutch (Van Eldik, Schlichting, Lutje-Spelberg, Van der Meulen, \& Van der Meulen, 1995), but is only suitable for young children aged 1 to 7 and therefore not appropriate for our study. Secondly, the NEPSY developmental neuropsychological assessment battery (Korkman, Kirk, \& Kemp, 1998) contains the subtest Comprehension of Instructions, which measures complex language comprehension. No Dutch version of this test is available as yet, and, in addition, it is only suitable up to age 12. Thus again, this test could not be used in our study. Finally, the Clinical Evaluation of Language Fundamentals-Third Edition (Semel, Wiig, \& Secord, 1995) contains a receptive index and is useful in children aged 5 to 16 . Unfortunately, no Dutch version of this test exists. Thus, none of the available clinical measures of complex language comprehension were suitable for the goals of this study. Therefore, we took an experimental approach to measure complex language comprehension.

Experimental studies on the development of complex language comprehension are rather limited. Dick, Wulfeck, Krupa-Kwiatkowski, and Bates (2004), in their study with 102 children aged 5 to 17 , demonstrated, using a multiple-choice paradigm, that the accuracy of and speed in choosing the agent in sentences improved up until the age of nine. Additionally, Booth, MacWhinney, and Harasaki (2000) noted a significant improvement in accuracy as children moved from a younger grade (third and fourth graders) to an older grade (fifth and sixth graders). However, the ecological validity of a multiple-choice paradigm appears to be limited. In the real world, children are rarely provided with two or more options to choose from when confronted with complex language. Differences between children with and without specific language impairment have been investigated using a second approach, namely the Wh-questions paradigm. In this paradigm, children are required to respond to what, where, when, and who questions (Deevy \& Leonard, 2004; Marton \& Schwartz, 2003). In a previous study with 83 children aged 6 to 12 from relatively high socioeconomic backgrounds (Wassenberg et al., 2007), we used the Wh-paradigm to investigate the language comprehension in normally developing children. The accuracy of language comprehension was measured using the neuropsychological procedure proposed by Luria $(1966,1980)$. The Luria approach was initially proposed for use with patients suffering from brain lesions. However, it was adapted by the research group for use in normally developing children. The results of this study indicated that some aspects of language comprehension were already mastered at the beginning of elementary school, while others became mastered sometime during elementary school, and still others were not yet mastered at the end of elementary school (age 12). We thus concluded that accuracy of complex language comprehension was probably not fully developed at the end of elementary school.

To extend these findings, we conducted a second cross-sectional study using a much larger sample of children. In contrast to our previous study, the present study included not only children attending elementary school but also children attending secondary school. Additionally, we aimed to include children from more diverse socioeconomic backgrounds. In the study presented here, the sample included 361 children, aged 5 to 15 , who were attending kindergarten and the second, fourth, sixth, seventh, and eighth grades (aged 5 to 15). This grade selection was chosen based on recent knowledge of the differential development of complex cognitive functions and the age at which these functions mature (Blakemore \& Choudhury, 2006; Crone, Bunge, van der Molen, \& Ridderinkhof, 2006; Luciana, Conklin, Hooper, \& Yarger, 2005; Shaw et al., 2006). In essence, we focused primarily on the age of 12 to 15 years as this is the age at which complex language comprehension is expected to mature. In doing so, we expected to be able to determine at exactly which age complex language comprehension is fully developed. Additionally, in the present study, two adaptations were made with respect to how language comprehension was measured. First, we included a larger sample so that we could effectively study both accuracy and speed of complex language comprehension. Studying both accuracy and speed of complex language comprehension was considered to improve the ecological validity of the study, given that, in 
real life, we rarely have time to reflect as we communicate (Dick et al., 2004). Secondly, we endeavored to acquire more knowledge on the processes within complex language comprehension so that more specific conclusions could be drawn about the maturation order of these different aspects. In other words, we were interested in uncovering which aspects of complex language comprehension mature at the earliest age and which continue to develop the longest. Therefore, we supplemented the Luria approach (Assessment Battery for Children-Language; ABC-L) that was used in the previous study by also using an adaptation of the Token Test (TT-A) in this study. The Token Test is a test in which children have to demonstrate that they understand increasingly complex commands by moving tokens accordingly (Lezak et al., 2004). Both approaches test the child's ability to understand sentences. The difference is related to the response output. In the ABC-L, mostly oral answers are required, whereas in the TT-A, motor answers are expected.

The second aim of the study was to investigate the influence of several age-extrinsic variables on language comprehension. These variables are mediating factors in a child's development. For example, parental education and occupation have a large impact on problem behavior and attention problems in 5- to 6-year-old children (Kalff et al., 2001a), as does living in a deprived environment (Kalff et al., 2001b). Additionally, with respect to early language development, previous research has demonstrated that girls have an advantage over boys (Bauer, Goldfield, \& Reznick, 2002; Dodd, Holm, Hua, \& Crosbie, 2003; Holm, Greaker, \& Stroemberg, 2002; Roulstone, Loader, Northstone, \& Beveridge, 2002; Tse, Kwon, Chan, \& Li, 2002), and that children from families with a high level of education generally develop faster than children with lower socioeconomic status (Dollaghan et al., 1999; Hoff, 2003; Jackson, 2003; Landry, Smith, \& Swank, 2002; Mackner, Black, \& Starr, 2003; Quay \& Blaney, 1992). Based on these results found with young children, we expected that complex language comprehension would mature at an earlier age in girls and in children whose parents are highly educated than it would in boys and in children from families with a lower level of education. These hypotheses were investigated in this study.

In summary, the aims of this study were, first, to investigate age differences in speed and accuracy of complex language comprehension in a large sample of healthy Dutch school children attending kindergarten through to the eighth grade, and, second, to study the influence of sex and parental level of education on this development. The strengths of the study include the wide age range tested (5-15 years), the sample size employed $(N=361)$, and our attempt to control for several variables that may alter the development of complex language comprehension (verbal intelligence and short-term memory).

\section{METHOD}

\section{Procedure}

This study is part of a large, ongoing research program that focuses on mechanisms underlying cognitive development in children. This program makes use of large scale cross-sectional and longitudinal experiments (e.g., Hurks et al., 2006; Kalff et al., 2005; Kroes et al., 2001). As the first step in the project, all schools for regular elementary education and three large schools for regular secondary education in Maastricht, a city in the southern region of the Netherlands, were approached. Schools that agreed to participate in the study received information packages for the parents of all children in the following grades: kindergarten; second, fourth, and sixth grades (elementary schools); seventh and eighth grades (secondary schools). The information packages for the parents contained a letter about the purpose of the study, a request to participate, and a stamped return envelope. Parents who agreed to participate also completed a questionnaire on sociodemographic characteristics and their child's medical history and milestone development.

Only children who had the Dutch nationality and who were in the appropriate grade were eligible for participation in the study (with the exception of children who remained in kindergarten an extra year because they were born in September and, as a result, were so called "young" pupils). The exclusion criterion was current use of medications that could influence cognitive functioning, such as antihistamines (prescribed for hay fever) and psychostimulants (prescribed for attention deficit hyperactivity disorder and autism spectrum disorders, among others). Children with developmental disorders such as dyslexia were not excluded from the study because we did not want a "supernormal" sample (the estimated prevalence of reading and spelling problems in Dutch elementary education is $8.8 \%$, and the prevalence of dyslexia is $3.6 \%$; Blomert, 2002). Rather, we reasoned that if children were attending a school for regular education and were in the appropriate grade, they could be considered as normally developing. We 
endeavored to include a reasonably equal number of boys and girls for each grade. We also aimed to include children from various socioeconomic backgrounds.

All children were tested individually in a stimulusfree test room at their school. Testing was conducted by well-trained graduate students majoring in developmental psychology or neuropsychology. The tests took approximately 90 minutes and were all administered in the same order for each child. A break halfway was included if necessary, for example because of fatigue. The cognitive battery that was administered focused on language and several other domains, such as memory, sense of time, and estimation. The study was approved by the ethical committee of the psychology department at Maastricht University.

\section{Participants}

Of the approximately 3,000 information packages that were sent out, 1,089 were returned (of these, $81.9 \%$ agreed to participate, $18.1 \%$ refused). Of the 892 children whose parents provided consent for the study, 450 were selected using the inclusion and exclusion criteria described above. Of these 450 children, 19 were excluded from the data analyses after the data were collected because the testing demonstrated that the inclusion or exclusion criteria had not been met. Of the remaining 431 children, data for 70 children were missing on one or more of the tests. Reasons for missing data were as follows: time scheduling problems $(n=31)$, technical problems $(n=9)$, and refusal of the child to comply with the test instructions (mainly because of fatigue, $n=30$ ). In the end, data were complete for 361 children, and only these children were included in the analyses. Table 1 shows the characteristics of these children.

\section{Instruments}

Complex language comprehension was investigated using two tasks. The first was the Assessment Battery for Children-Language (ABC-L for short; Wassenberg et al., 2007), which is part of a more extensive language comprehension battery developed by Luria $(1966,1980)$ and adapted by Christensen (1993). A total of 11 of the 24 items in the original battery were administered. Items that would have been too easy for school-age children were not used in the present study (they were developed by Luria for the assessment of patients with brain injuries; an example is "pointing to objects"). The ABC-L items (shown in Table 2) were read aloud to the child by the experimenter, and the experimenter noted the child's answer. The time that each item took was noted as well. Items were repeated as often as requested, which was reflected in the notation of a longer duration in response. The ABC-L took about 10 minutes to administer. Each correct answer was awarded 1 point (maximum score possible $=13$ points). The $\mathrm{ABC}-\mathrm{L}$ proportion correct (ABC-L accuracy) and the mean time per item (ABC-L speed) were used in the analyses.

The second measure used for language comprehension was an Adapted Version of the Token Test (abbreviated as TT-A in the rest of the text). The

TABLE 1

Characteristics of the participants

\begin{tabular}{lllcccccc}
\hline & & \multicolumn{1}{c}{$\begin{array}{c}6 \\
(N=52)\end{array}$} & $\begin{array}{c}2 \\
(N=62)\end{array}$ & $\begin{array}{c}4 \\
(N=66)\end{array}$ & $\begin{array}{c}6 \\
(N=64)\end{array}$ & $\begin{array}{c}7 \\
(N=66)\end{array}$ & $\begin{array}{c}8 \\
(N=51)\end{array}$ & Statistic \\
\hline Age & $M(S D)$ & $6.4(0.4)$ & $8.4(0.4)$ & $10.4(0.3)$ & $12.4(0.3)$ & $13.4(0.4)$ & $14.5(0.3)$ & $4,492.0^{\mathrm{a}, * *}$ \\
Sex & boys & 44.2 & 50.0 & 42.4 & 48.4 & 56.1 & 58.8 & $4.8^{\mathrm{c}}$ \\
& girls $^{\mathrm{b}}$ & 55.8 & 50.0 & 57.6 & 51.6 & 43.9 & 42.2 & \\
LPE & L/M $^{\mathrm{b}}$ & 46.2 & 38.7 & 47.0 & 70.3 & 36.4 & 49.0 & $7.0^{\mathrm{c}}$ \\
& $\mathrm{H}^{\mathrm{b}}$ & 53.8 & 61.3 & 53.0 & 29.7 & 63.6 & 51.0 & \\
VIQ & $M(S D)$ & $11.1(3.0)$ & $10.7(2.9)$ & $10.5(2.6)$ & $10.0(1.9)$ & $10.0(2.1)$ & $9.8(2.2)$ & $2.3^{\mathrm{a}, *}$ \\
MEM & $M(S D)$ & $4.9(1.4)$ & $6.0(1.9)$ & $6.6(1.9)$ & $7.6(1.8)$ & $7.8(1.9)$ & $7.8(1.6)$ & $23.8^{\mathrm{a}, * *}$ \\
\hline
\end{tabular}

Note. $\mathrm{K}=$ kindergarten; $2=2^{\text {nd }}$ grade $4=4^{\text {th }}$ grade; $6=6^{\text {th }}$ grade $7=7^{\text {th }}$ grade $; 8=8^{\text {th }}$ grade LPE $=$ level of parental education: $\mathrm{L} / \mathrm{M}=$ low/medium, $\mathrm{H}=$ high (Dictoraat-Generaal voor de Arbeidsvoorziening, 1989); VIQ=estimate of verbal intelligence, measured with the Vocabulary subtest of the Wechsler Intelligence Scale for Children-Revised (WISC-R; De Bruyn et al., 1986); MEM=Shortterm memory, measured with a version of the Word Learning Test (Lezak et al., 2004).

${ }^{\mathrm{a} O n e-w a y ~ a n a l y s i s ~ o f ~ v a r i a n c e ~}(d f 1=5, d f 2=355)$.

${ }^{\mathrm{b}}$ In percentages.

${ }^{\mathrm{c} C h i}$-square test $(d f=5)$.

$* p<.05$.

$* * p<.001$. 
original Token Test assesses verbal comprehension of increasing complex commands (De Renzi \& Faglioni, 1978) and is generally used to screen for aphasia. Nonaphasic persons who have completed the fourth grade are expected to perform with few, if any, errors (Lezak et al., 2004). The test requires participants to move tokens according to oral commands provided by the experimenter. There are 20 tokens in two shapes (circles and rectangles), two sizes (big and little), and five colors (red, blue, yellow, white, and green). The tokens are laid out horizontally in parallel rows with colors in fixed order per row (Lezak et al., 2004). ${ }^{1}$ The adapted version used in this study consisted of: (a) Part V of the original Token Test, which involves relational concepts and is considered to be the most difficult part (Lezak et al., 2004); and (b) a 9-item self-developed part in which the same type of relational concepts as those in Part V are tested. However, in this part, not only large rectangles and circles are used. Small rectangles and circles are also used. For example, for the following item of Part $\mathrm{V}$ of the original Token Test "Pick up the rectangles, except the yellow one," the instruction was changed to "Pick up the rectangles, except the small yellow one." This adapted part of the TT-A was included to increase the complexity and, in doing so, make the test more suitable for children as well as adolescents (in contrast to the original Token Test for Children, which is appropriate for children aged 3 to 12, DiSimoni, 1978, and the Revised Token Test, which is suitable from age 20 on, McNeil \& Prescott, 1978). The TTA consisted of 27 items in total (see Table 2). Administration of the TT-A was similar to that of the ABC-L in that the items were read aloud to the child by the experimenter. The child responded by moving the tokens, and the experimenter noted not only whether the response was correct or false but also the time taken to respond to each item. Again, items could be repeated as often as requested, and this was reflected in the notation of a longer duration in response on that item.

To make the 90-minute test session as diverse as possible, the TT-A was divided in half (14 items, 13 items). The first half was administered after approximately 20 minutes, and the second was administered after approximately an hour. Total administration time of both halves was about 15 minutes. Each correct answer was awarded 1 point (maximum score

\footnotetext{
${ }^{1}$ In English-speaking areas, rectangles have been substituted by squares, to reduce the number of syllables that must be processed. In Dutch, however, this has never been necessary because the Dutch words for rectangle ("rechthoek") and square ("vierkant") both contain two syllables.
}

possible $=27$ points). The TT-A proportion correct (TT-A accuracy) and the mean time per item (TT-A speed) were used in the analyses.

To control for the influence of short-term memory on comprehension of complex language (Baddeley, 2003; Booth et al., 2000; Carpenter, Miyake, \& Just, 1994; Deevy \& Leonard, 2004; Dick et al., 2004; Hahne, Eckstein, \& Friederici, 2004; Helland \& Asbjornsen, 2004; Just \& Carpenter, 1992; Marton \& Schwartz, 2003; Montgomery, 2003), we used the first trial of a Word Learning Test (WLT; Lezak et al., 2004; Meijs, Hurks, Wassenberg, Feron, \& Jolles, 2007). In this test, children were shown 15 unrelated pictures or were presented 15 unrelated words on a laptop computer. Immediately after all pictures/words were presented, children were instructed to name as many as possible. The total number of correctly reproduced words was recorded and were used in the analyses. The different modalities and versions of the test had no influence on the language comprehension scores and, as a result, were not be used in the analyses. Table 1 indicated that WLT scores improved significantly over the grades. Post hoc Bonferroniadjusted comparisons showed a stage-like linear improvement. Only the differences between second and fourth grades and the sixth, seventh, and eighth grades were not significant. Because of these age differences and the expected influence of shortterm memory on complex language comprehension, the WLT raw score (range $=0-15$ ) was included in all analyses as a covariate.

Verbal intelligence was estimated using the Vocabulary subtest of the Dutch Wechsler Intelligence Scale for Children Revised (WISC-R; De Bruyn et al., 1986; Wechsler, 1974). The WISC-R, rather than the WISC-III, was used because the latter became available in the Netherlands only after the study had started. In the Vocabulary subtest, children were required to define a number of words as accurately and completely as they could. Scaled scores ranging from 1 to $19(M=10$, $S D=3$ ) were used as the outcome variable. Although the Vocabulary scores appeared to differ between the grades (see Table 1), post hoc Bonferroni-corrected comparisons were not significant. Because of the expected relationship between vocabulary and complex language comprehension, vocabulary was included in all analyses as a covariate.

Level of parental education was based on the partner with the highest level of education (Kalff et al., 2001a). The majority of participants came from families with a moderate to high level of education. A total of 28 parent pairs $(7.7 \%)$ had a low level of parental education, 122 parent pairs 
TABLE 2

ABC-L and TT-A items

\begin{tabular}{|c|c|c|c|c|c|c|c|c|}
\hline \multirow[b]{2}{*}{ Task } & \multirow[b]{2}{*}{ No. } & \multirow[b]{2}{*}{ Item } & \multicolumn{6}{|c|}{ Proportion correct } \\
\hline & & & $K$ & 2 & 4 & 6 & 7 & 8 \\
\hline \multirow[t]{14}{*}{ ABC-L } & 1. $\mathrm{M}$ & Is my father's brother the same person as my brother's father? (13) & .76 & .74 & .68 & .82 & .89 & .88 \\
\hline & 2. $\mathrm{M}$ & Draw a cross beneath a circle $(6)$ & .73 & .94 & .93 & .97 & .99 & .98 \\
\hline & 3. $\mathrm{M}$ & Draw a circle to the right of a cross (7) & .48 & .73 & .97 & .95 & .97 & .97 \\
\hline & 4. $\mathrm{H}$ & Draw a circle to the right of a cross but to the left of a triangle (12) & .10 & .25 & .49 & .83 & .81 & .78 \\
\hline & 5. M & $\begin{array}{l}\text { Which is correct: "Spring comes before summer" or "Summer comes before } \\
\text { spring"? (18) }\end{array}$ & .80 & .74 & .93 & .97 & .94 & .93 \\
\hline & 6. $\mathrm{M}$ & Who is smallest if John is taller than Pete? (11) & .72 & .84 & .97 & .97 & .94 & .93 \\
\hline & 7. E & $\begin{array}{l}\text { Which is correct: "A fly is bigger than an elephant" or "An elephant is } \\
\text { bigger than a fly"? (18) }\end{array}$ & .98 & 1 & 1 & 1 & 1 & .98 \\
\hline & 8a. H & Which girl is lightest if Olga is lighter than Sonia but darker than Kate? (15) & .33 & .56 & .69 & .82 & .83 & .78 \\
\hline & 8b. H & And which girl is darkest? (6) & .27 & .53 & .56 & .74 & .73 & .62 \\
\hline & 9. M & Nick was struck by Pete. Who was the victim? (9) & .35 & .62 & .89 & .97 & .94 & .92 \\
\hline & 10. M & I had breakfast after I had walked the dog. What did I do first? (13) & .45 & .67 & .78 & .86 & .90 & .95 \\
\hline & 11a. $\mathrm{H}$ & $\begin{array}{l}\text { The girl who worked in the zoo came to Margaret's school to give a } \\
\text { presentation. Who gave the presentation? (24) }\end{array}$ & .62 & .79 & .58 & .76 & .77 & .79 \\
\hline & 11b. H & What did Margaret do? (3) & .27 & .59 & .50 & .73 & .75 & .79 \\
\hline & Total & & .53 & .69 & .75 & .87 & .88 & .87 \\
\hline \multirow[t]{28}{*}{ TT-A } & 1. $\mathrm{M}$ & Put the red circle on the green rectangle ( 8 ) & .92 & .84 & .93 & .89 & .90 & .95 \\
\hline & 2. $\mathrm{H}$ & Touch the blue circle with the red rectangle (9) & .13 & .32 & .43 & .42 & .70 & .72 \\
\hline & 3. $\mathrm{M}$ & Touch, with the blue circle, the red rectangle (9) & .82 & .87 & .92 & .89 & .93 & .93 \\
\hline & 4. $\mathrm{M}$ & Pick up the blue circle or the red rectangle (9) & .71 & .88 & .94 & .99 & .97 & .97 \\
\hline & 5. M & Move the green rectangle away from the yellow rectangle (9) & .63 & .77 & .90 & .96 & .94 & .97 \\
\hline & 6. M & If there is a black circle, pick up the red rectangle (12) & .73 & .71 & .89 & .96 & .96 & .95 \\
\hline & 7. E & Pick up the rectangles, except the yellow one (7) & .98 & .97 & 1 & 1 & 1 & 1 \\
\hline & 8. E & When I touch the green circle, you take the white rectangle (12) & .89 & .96 & .97 & .86 & .93 & 1 \\
\hline & 9. M & Put the green rectangles beside the red circle (8) & .77 & .93 & .93 & 1 & .99 & .97 \\
\hline & 10. $\mathrm{M}$ & Touch the rectangles, slowly, and the circles, quickly (16) & .45 & .68 & .72 & .77 & .89 & \\
\hline & 11. E & Put the red circle between the yellow rectangle and the green rectangle (12) & .89 & .94 & .93 & .96 & .96 & .93 \\
\hline & 12. $\mathrm{M}$ & Except for the green one, touch the circles (7) & .74 & .99 & .99 & .99 & 1 & 1 \\
\hline & 13. E & Pick up the red circle - no! - the white rectangle (9) & .95 & .93 & .96 & .96 & .99 & .97 \\
\hline & 14. $\mathrm{M}$ & Instead of the white rectangle, take the yellow circle (10) & .82 & .94 & .97 & .94 & .99 & 1 \\
\hline & 15. E & Together with the yellow circle, take the blue circle (9) & .94 & 1 & .97 & .99 & .99 & 1 \\
\hline & 16. $\mathrm{M}$ & After picking up the green rectangle, touch the white circle (13) & .61 & .81 & .92 & .92 & .87 & .97 \\
\hline & 17. E & Put the blue circle under the white rectangle (8) & .94 & .91 & .96 & .99 & 1 & 1 \\
\hline & 18. M & Before touching the yellow circle, pick up the red rectangle (12) & .60 & .83 & .89 & .99 & .96 & .98 \\
\hline & 19. $\mathrm{H}$ & Touch the little yellow circle with the large green rectangle (11) & .37 & .57 & .60 & .68 & .81 & \\
\hline & 20. $\mathrm{M}$ & Put the large green circle on the small white rectangle (10) & .61 & .83 & .89 & .86 & .91 & .88 \\
\hline & 21. $\mathrm{M}$ & Before touching the small white circle, pick up the large green rectangle (14) & .57 & .78 & .90 & .89 & .96 & .93 \\
\hline & 22. $\mathrm{M}$ & Pick up the rectangles, except the small blue one (8) & .53 & .75 & .88 & .94 & .97 & .97 \\
\hline & 23. $\mathrm{M}$ & Touch, with the large white circle, the small blue rectangle (11) & .55 & .77 & .88 & .91 & .96 & .8 \\
\hline & 24. $\mathrm{M}$ & Put the small red rectangle next to the small blue circle (10) & .57 & .83 & .90 & .97 & .94 & \\
\hline & 25. M & After picking up the large red rectangle, pick up the small yellow circle (15) & .29 & .57 & .64 & .74 & .77 & .90 \\
\hline & 26. M & Pick up the large green circle or the small yellow rectangle (11) & .76 & .83 & .90 & .91 & .96 & .98 \\
\hline & 27. $\mathrm{M}$ & Touch the circles, except the large white one (8) & .48 & .67 & .87 & .96 & .96 & .88 \\
\hline & Total & & .68 & .81 & .88 & .90 & .93 & .94 \\
\hline
\end{tabular}

Note. Number of words in Dutch item shown in parentheses. ABC-L =Assessment Battery for Children-Language. TT-A=Adapted Version of the Token Test. $\mathrm{K}=$ kindergarten; $2=2^{\text {nd }}$ grade; $4=4^{\text {th }}$ grade; $6=6^{\text {th }}$ grade; $7=7^{\text {th }}$ grade; $8=8^{\text {th }}$ grade; $E=$ easy item: proportion correct is above $85 \%$ in all grades; $\mathrm{M}=$ medium complex item: proportion correct is below $85 \%$ in some grades but above $85 \%$ correct in the highest grade(s); $\mathrm{H}=$ hard item: proportion correct is below $85 \%$ correct in all grades. TT-A Items 1 to 18 were retrieved from Lezak et al., 2004.

$(33.5 \%)$ had a moderate level, and 214 parent pairs $(58.8 \%)$ had a high level of education (DirectoraatGeneraal voor de Arbeidsvoorziening, 1989). Because only a few parent pairs had a low level of education, the level of parental education was scored on a 2-point scale: low/middle (1 point, elementary school to vocational education degree) versus high ( 2 points, general secondary education to doctoral degree). The level of parental education did not differ between the grades (see Table 1). 


\section{Statistical analyses}

The statistical package SPSS 11.5 was used for all analyses. Because the ABC-L and TT-A speed scores were not normally divided, their logarithmic transformations were used in the analyses. Specific group differences for accuracy and speed for the ABC-L and the TT-A were each analyzed with five separate linear regression analyses. In these analyses, one of the grades was systematically compared with the others. This was done by including one of four sets of dummy variables. For example, with the dummy variables of kindergarten, the following comparisons were made: kindergarten with second grade, kindergarten with fourth grade, kindergarten with sixth grade, kindergarten with seventh grade, and kindergarten with eighth grade. No set of dummy variables was needed for the oldest grade because all comparisons had been made already. Additional variables included in the analyses were sex (coded as: boy $=1$, girl=2), parental level of education (coded as: low/middle $=1$, high $=2$ ), estimate of verbal intelligence (continuous), and estimate of short-term memory (continuous). The alpha value was set at .05 for all analyses.

\section{RESULTS}

\section{Descriptives}

Internal consistency of the ABC-L and TT-A speed and accuracy scores were calculated using Cronbach's alpha. Results were as follows: Cronbach's alpha $=.80$ for ABC-L speed, .73 for ABC-L accuracy, .92 for TT-A speed, and .79 for TT-A accuracy.

Correlations between the scores on the ABC-L and TT-A, corrected for grade, were calculated with Pearson correlation coefficients. We found positive and significant correlations between the ABC-L and TT-A accuracy scores $(\rho=.382, p<$ $.001)$ and between the ABC-L and TT-A speed scores $(\rho=.429, p<.001)$. Speed and accuracy scores of the TT-A were found to correlate negatively and significantly $(\rho=-.264, p<.001)$ whereas no significant correlation was found between the ABC-L speed and accuracy scores $(\rho=-.032$, $p=.553$ ). With regard to the association of speed and accuracy over the tests, a small negative correlation was found between ABC-L accuracy and TT-A speed ( $\rho=-.107, p=.049)$, and no significant correlation was found between ABC-L speed and TT-A accuracy $(\rho=-.029, p=.597)$. This indicates that there is no strong relation between speed and accuracy of language comprehension, when the effect of grade is partialled out.
As a general rule, an aspect of language comprehension was considered to be "mastered" if at least $85 \%$ of the children within a certain group answered it correctly. One ABC-L item could be classified as "easy" according to this rule. The proportion of correct answers on this item was above .85 for all grades. For the TT-A, 6 items could be classified as "easy" (see items marked with E in Table 2). Items on which performance was below .85 in some grades but above .85 in the highest grades were classified as "medium complex." A total of 7 ABC-L and 19 TT-A items fit this description (see items marked with $M$ in Table 2). The most difficult items, on which the proportion correct was below .85 in all grades, were classified as "hard." A total of 5 ABC-L items and 2 TT-A items fit this description (see items marked with $\mathrm{H}$ in Table 2). These most difficult items were grammatically ambiguous and consisted of at least three concepts to compare (e.g., "Draw a circle to the right of a cross but to the left of a triangle"). A oneway analysis of variance indicated that the mean number of words per item differed significantly between the three complexity levels: easy, $M=10.7$, $S D=3.7$; medium, $M=10.7, \quad S D=3.0$; hard, $M=17.0, S D=7.0, F(2,37)=7.15, p=.002$. The mean logarithmic transformation of speed per item, however, did not differ significantly between the three complexity levels: easy, $M=0.97 \mathrm{~s}$, $S D=0.09$; medium, $M=1.05 \mathrm{~s}, S D=0.13$; hard, $M=1.03 \mathrm{~s}, S D=0.13, F(2,37)=1.27, p=.293$.

\section{Age-related differences: Accuracy}

Figure 1A shows the developmental pattern for total accuracy of language comprehension on the TT-A and ABC-L. Not surprisingly, accuracy increased from the lower grades through to the older grades. Table 3 shows the results of the linear regression analyses for accuracy of language comprehension. TT-A and ABC-L accuracy both improved linearly from kindergarten to the sixth grade. The differences between performance in the sixth, seventh, and eighth grades were not significant, although a trend for significance could be observed for the difference between the sixth and eighth grades on the TT-A. It thus appears that accuracy of complex language comprehension reached full development in the sixth grade.

With regard to the influence of age-extrinsic variables on the accuracy of complex language comprehension, we found that sex was not significantly related to performance on the TT-A and ABC-L accuracy scores. Boys and girls performed at equal levels. Level of parental education was, however, significantly associated with performance on the 


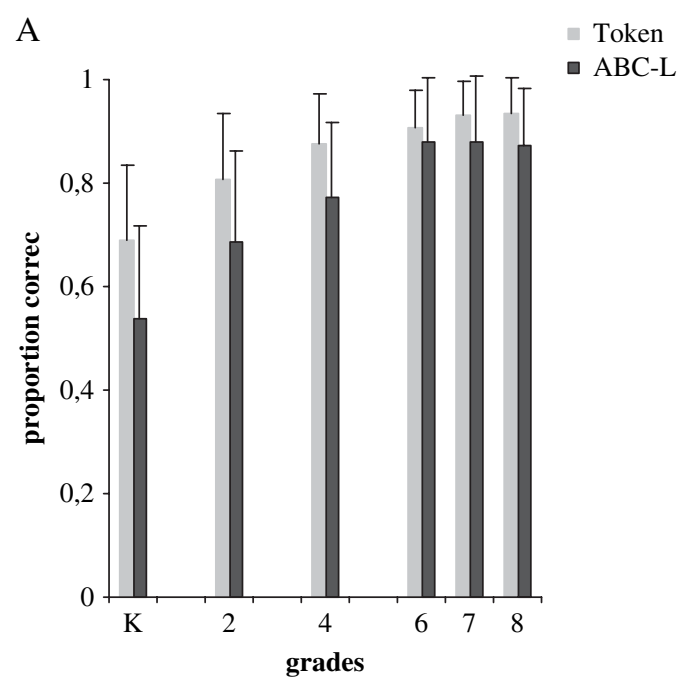

B

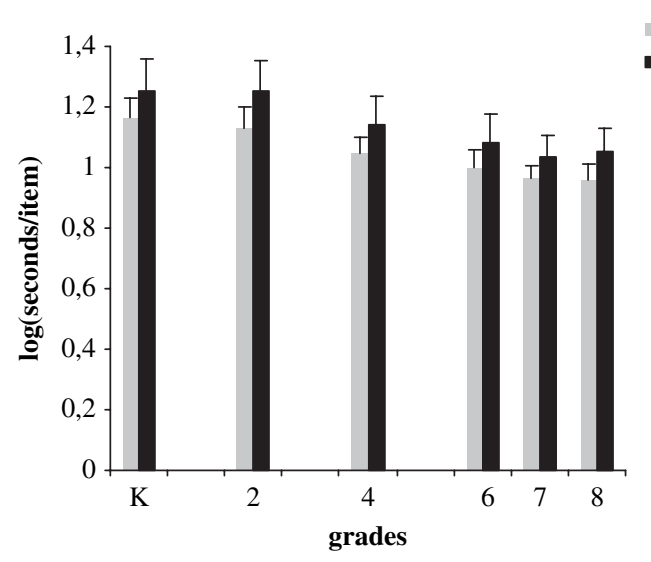

Figure 1. (A) Proportion correct on the language comprehension measures over the grades. (B) Logarithmic transformation of mean seconds per item over the grades.

ABC-L. Children with highly educated parents scored, on average, $3 \%$ better than children from low/middle education backgrounds. The TT-A accuracy score did not differ between children from low/middle and highly educated families.

\section{Age-related differences: Speed}

Figure 1A shows the developmental pattern for speed of language comprehension on the TT-A and ABC-L. Not surprisingly, speed decreased over the grades tested. Table 4 shows the results of the linear regression analyses for the logarithmic transformation of speed of language comprehension. Speed of language comprehension appeared to improve a year longer than accuracy, thus until the seventh grade. TT-A speed improved linearly from kindergarten to the seventh grade, whereas the difference between performance in the seventh grade and performance in the eighth grade was not significant. For the ABC-L, a slightly different pattern was observed. The difference between performance in kindergarten and second grade was not significant, and thus speed on this measure started to improve at a later age. In addition, the difference between speed of performance in the sixth and eighth grades on the ABC-L was such that only a statistical trend for significance could be demonstrated.

With regard to the influence of age-extrinsic variables on speed of complex language comprehension, we found that sex was not significantly related to performance on the ABC-L. Boys and girls performed with almost equal speed. Performance on the TT-A, however, was faster for girls than for boys. Level of parental education was not significantly associated with TT-A and ABC-L speed of processing. Children from families with a low/middle education level and children from families with a high education level performed equally fast.

\section{DISCUSSION}

We studied the age-related improvement of complex language comprehension and the influence of sex and parental level of education on this improvement in a sample of 361 normally developing children attending kindergarten and second, fourth, sixth, seventh, and eighth grades. Language comprehension was measured using an adaptation to the neuropsychological approach described by Luria (1966, 1980; Christensen, 1993) and by means of an adapted version of the Token Test (De Renzi \& Faglioni, 1978). The analyses were controlled for levels of verbal intelligence and shortterm memory. Perfect language comprehension was not reached in the age period studied. The findings show that the most complex sentences were not mastered completely by the eighth grade, and this suggests that the complex sentences were too difficult for 14-year-old adolescents. This interpretation is supported by our finding that complex language comprehension appeared to plateau, for accuracy, in the sixth grade and, for speed, in the seventh grade. We can thus contend that complex language comprehension continues to mature until early adolescence. This finding corresponds with and extends Peter Anderson's (2002) executive function model. Peter Anderson (2002) concluded that the cognitive domains of cognitive flexibility, goal setting, and information processing are relatively mature by early adolescence (12 years of age). Other cognitive functions that have been found to continue developing into adolescence are working memory and control of impulsivity 
TABLE 3

Linear regression models for accuracy of language comprehension

\begin{tabular}{|c|c|c|c|c|c|c|c|c|}
\hline \multirow[b]{2}{*}{ Differences } & \multicolumn{4}{|c|}{$\begin{array}{c}T T-A F(9,341)=37.6 \\
p<.001 R^{2}=49.8 \%\end{array}$} & \multicolumn{4}{|c|}{$\begin{array}{c}A B C-L F(9,349)=39.3 \\
p<.001 R^{2}=50.3 \%\end{array}$} \\
\hline & $B$ & $S E$ & $\beta$ & p-value & $B$ & $S E$ & $\beta$ & $p$-value \\
\hline $\mathrm{K}<2^{\text {nd }}$ grade & .12 & .02 & .36 & .000 & .16 & .03 & .32 & .000 \\
\hline $\mathrm{K}<4^{\text {th }}$ grade & .19 & .02 & .59 & .000 & .24 & .03 & .50 & .000 \\
\hline $\mathrm{K}<6^{\text {th }}$ grade & .23 & .02 & .70 & .000 & .35 & .03 & .72 & .000 \\
\hline $\mathrm{K}<7^{\text {th }}$ grade & .25 & .02 & .78 & .000 & .35 & .03 & .73 & .000 \\
\hline $\mathrm{K}<8^{\text {th }}$ grade & .26 & .02 & .73 & .000 & .36 & .03 & .67 & .000 \\
\hline $2^{\text {nd }}<4^{\text {th }}$ grade & .07 & .02 & .22 & .000 & .08 & .02 & .17 & .001 \\
\hline $2^{\text {nd }}<6^{\text {th }}$ grade & .11 & .02 & .33 & .000 & .19 & .03 & .40 & .000 \\
\hline $2^{\text {nd }}<7^{\text {th }}$ grade & .13 & .02 & .41 & .000 & .20 & .03 & .40 & .000 \\
\hline $2^{\text {nd }}<8^{\text {th }}$ grade & .14 & .02 & .40 & .000 & .20 & .03 & .37 & .000 \\
\hline $4^{\text {th }}<6^{\text {th }}$ grade & .04 & .02 & .12 & .020 & .11 & .02 & .23 & .000 \\
\hline $4^{\text {th }}<7^{\text {th }}$ grade & .06 & .02 & .19 & .000 & .11 & .02 & .23 & .000 \\
\hline $4^{\text {th }}<8^{\text {th }}$ grade & .07 & .02 & .20 & .000 & .12 & .03 & .22 & .000 \\
\hline $6^{\text {th }}<7^{\text {th }}$ grade & .02 & .02 & .07 & .154 & .00 & .02 & .001 & .990 \\
\hline $6^{\text {th }}<8^{\text {th }}$ grade & .03 & .02 & .09 & .062 & .01 & .03 & .01 & .810 \\
\hline $7^{\text {th }}<8^{\text {th }}$ grade & .01 & .02 & .03 & .586 & .01 & .03 & .01 & .817 \\
\hline Sex & .004 & .01 & .01 & .721 & -.01 & .01 & -.02 & .659 \\
\hline LPE & -.01 & .01 & -.05 & .260 & .03 & .02 & .08 & .032 \\
\hline VIQ & .02 & .002 & .29 & .000 & .02 & .003 & .27 & .000 \\
\hline MEM & .002 & .003 & .04 & .389 & .002 & .004 & .03 & .538 \\
\hline
\end{tabular}

Note. Accuracy is defined as the proportion correct. ABC-L = Assessment Battery for Children-Language. TT-A=Adapted Version of the Token Test. $\mathrm{K}=$ kindergarten. $B=$ unstandardized regression coefficient. $S E=$ standard error. $\beta=$ standardized regression coefficient. LPE=level of parental education (Directoraat-Generaal voor de Arbeidsvoorziening, 1989). VIQ=estimate of verbal intelligence, measured with the Vocabulary subtest of the Wechsler Intelligence Scale for Children-Revised (WISC-R; De Bruyn et al., 1986). MEM = short-term memory, measured with a version of the Word Learn Test (Lezak et al., 2004).

(Brocki \& Bohlin, 2004; Casey et al., 2005; Eslinger et al., 2004; Fuster, 2002; Paus, 2005; Steinberg, 2005). The findings of the present study add the construct "complex language comprehension" to the existing list of cognitive functions that continue to develop beyond childhood and into adolescence. This could have significant implications for the practice of education. Children may, at the end of elementary school, be less able to comprehend multifaceted tasks and instructions than we previously expected. Instructions containing several steps, such as "Take your workbook, open it to page 34, and start working on Assignment B" should be divided in several short sentences as this would allow teachers to check whether children did indeed understand the instructions. Although this kind of practice is already common in early elementary education and in schools for children with special needs, this study indicates that normally developing children up to the eighth grade may also benefit from simpler instructions.

Using the $85 \%$ correct rule (an aspect of language comprehension was considered to be mastered when $85 \%$ of children in a certain age group answered it correctly), the results showed that 7 of the 40 complex sentences tested here were already mastered in the earliest grades of elementary school while other sentences had not yet mastered in the eighth grade. However, most of the complex sentences (26) were mastered by students over the course of elementary and early secondary education. The most difficult items possessed strong grammatical complexity and ambiguity in contrast to the other items (Clifton \& Duffy, 2001; Dennis $\&$ Barnes, 1990). For example, one of the most difficult items was "Touch the blue circle with the red rectangle." To understand this item, children have to be aware that the order of the words is not similar to the actions they are supposed to execute. First, they must pick up the red rectangle and then they have to use this token to touch the blue square. Thus, in the comprehension process of such sentences, both content and structure have to be incorporated.

Another potential explanation for this differential development of complex language comprehension can be derived from the length of the items in the three complexity levels. The most difficult items all contained at least three concepts to compare, whereas less difficult items contained two 
TABLE 4

Linear regression models for speed of language comprehension

\begin{tabular}{|c|c|c|c|c|c|c|c|c|}
\hline \multirow[b]{2}{*}{ Differences } & \multicolumn{4}{|c|}{$\begin{array}{c}T T-A F(9,342)=77.8 \\
p<.001 R^{2}=67.2 \%\end{array}$} & \multicolumn{4}{|c|}{$\begin{array}{c}A B C-L F(9,349)=34.1 \\
\quad p<.001 R^{2}=46.8 \%\end{array}$} \\
\hline & $B$ & $S E$ & $\beta$ & $p$-value & $B$ & $S E$ & $\beta$ & $p$-value \\
\hline $\mathrm{K}<2^{\text {nd }}$ grade & -.035 & .011 & -.136 & .002 & .002 & .017 & .006 & .909 \\
\hline $\mathrm{K}<4^{\text {th }}$ grade & -.117 & .011 & -.467 & .000 & -.111 & .017 & -.342 & .000 \\
\hline $\mathrm{K}<6^{\text {th }}$ grade & -.161 & .012 & -.645 & .000 & -.164 & .018 & -.499 & .000 \\
\hline $\mathrm{K}<7^{\text {th }}$ grade & -.201 & .012 & -.811 & .000 & -.213 & .018 & -.653 & .000 \\
\hline $\mathrm{K}<8^{\text {th }}$ grade & -.203 & .012 & -.743 & .000 & -.197 & .019 & -.547 & .000 \\
\hline $2^{\text {nd }}<4^{\text {th }}$ grade & -.082 & .010 & -.329 & .000 & -.113 & .016 & -.348 & .000 \\
\hline $2^{\text {nd }}<6^{\text {th }}$ grade & -.127 & .010 & -.507 & .000 & -.166 & .017 & -.505 & .000 \\
\hline $2^{\text {nd }}<7^{\text {th }}$ grade & -.166 & .010 & -.672 & .000 & -.215 & .017 & -.659 & .000 \\
\hline $2^{\text {nd }}<8^{\text {th }}$ grade & -.168 & .011 & -.617 & .000 & -.199 & .018 & -.553 & .000 \\
\hline $4^{\text {th }}<6^{\text {th }}$ grade & -.045 & .010 & -.178 & .000 & -.053 & .016 & -.162 & .001 \\
\hline $4^{\text {th }}<7^{\text {th }}$ grade & -.084 & .010 & -.338 & .000 & -.102 & .016 & -.313 & .000 \\
\hline $4^{\text {th }}<8^{\text {th }}$ grade & -.086 & .011 & -.314 & .000 & -.086 & .017 & -.239 & .000 \\
\hline $6^{\text {th }}<7^{\text {th }}$ grade & -.039 & .010 & -.158 & .000 & -.049 & .016 & -.151 & .002 \\
\hline $6^{\text {th }}<8^{\text {th }}$ grade & -.041 & .011 & -.151 & .000 & -.033 & .017 & -.092 & .051 \\
\hline $7^{\text {th }}<8^{\text {th }}$ grade & -.002 & .010 & -.007 & .848 & .016 & .017 & .045 & .337 \\
\hline Sex & -.015 & .006 & -.078 & .014 & -.014 & .010 & -.054 & .154 \\
\hline LPE & .001 & .006 & .004 & .901 & -.015 & .010 & -.059 & .128 \\
\hline VIQ & -.005 & .001 & -.125 & .000 & -.007 & .002 & -.144 & .000 \\
\hline MEM & -.004 & .002 & -.087 & .015 & -.005 & .003 & -.077 & .078 \\
\hline
\end{tabular}

Note. Speed is defined as the logarithmic transformation of the mean duration of items in seconds. ABC-L=Assessment Battery for Children-Language. TT-A=Adapted Version of the Token Test. K=kindergarten. $B=$ unstandardized regression coefficient. $S E=$ standard error. $\beta=$ standardized regression coefficient. LPE = level of parental education (Directoraat-Generaal voor de Arbeidsvoorziening, 1989). VIQ= estimate of verbal intelligence, measured with the Vocabulary subtest of the Wechsler Intelligence Scale for Children-Revised (WISC-R; De Bruyn et al., 1986). MEM=short-term memory, measured with a version of the Word Learn Test (Lezak et al., 2004).

concepts at most. We found that the items that were not yet mastered in the highest grades were, on average, longer than the items that were mastered in the lower grades. This characteristic appears to point to the well-established relationship between memory and language comprehension (Baddeley, 2003; Luria, 1966, 1980). When we looked at the total scores, we found that children with a larger memory span comprehended the complex sentences faster. However, no relationship between short-term memory and the accuracy of complex language comprehension was found. This distinction probably stems from the fact that, in this study, the language comprehension items could be repeated as often as requested, which may have actually represented a slower speed of comprehension on that item. In essence, children with higher levels of short-term memory likely asked for repetition less often and, as a result, had higher levels of speed. However, because no strong relationship between accuracy and speed of language comprehension was found, we can contend that, when the effect of grade was not considered, a faster response did not automatically imply a correct response.
Speed of complex language comprehension continued to improve for a year longer than accuracy. This suggests that speed is more sensitive to developmental changes in language comprehension than accuracy is. A line of research that is related to this finding comes from Hale (1990) and Kail (1991, 1996, 2000). These researchers focused on the development of general processing speed measured by reaction time tests on different domains of cognitive functioning (e.g., mental rotation, letter matching, and abstract matching). They demonstrated that the reaction times of children and adolescents continued to decrease until about the age of 15 , at which time adult levels were reached. According to Kail (1991), age differences in processing speed reflect a general component that changes rapidly during childhood and more slowly during adolescence. This prolonged development of processing speed has been explained by neural processes such as myelinization and synaptogenesis (see Kail, 1996; Travis, 1998).

The second aim of this study was concerned with the influence of two age-extrinsic variables on the comprehension of complex language. These two 
variables were sex and parental level of education. Our expectation that girls would have an advantage over boys was confirmed for speed of language comprehension. Girls did indeed, on average, perform faster than boys on the TT-A. However, no influence of sex was found for the accuracy of language comprehension. In other words, boys and girls were equally able to understand complex sentences but girls were faster in giving the correct answer. Therefore, the advantage girls have over boys that has been demonstrated in young children (Bauer et al., 2002; Dodd et al., 2003; Holm et al., 2002; Roulstone et al., 2002; Tse et al., 2002) appears to be more specific in children and adolescents between the ages of 5 and 15 . Knowledge from adult cognitive psychology may be relevant in this context. In this field, research has shown that, on cognitive tasks, 40year-old individuals can perform with the same accuracy as 25-year-olds. However, 40-year-olds need considerably more time to do so (Van der Elst, van Boxtel, van Breukelen, \& Jolles, 2006). Hence, when speed is emphasized, 40-year-olds perform much worse than 25-year-olds. A similar mechanism may be present in 5- to 15-year-old children with girls comprehending complex language faster than boys. This obviously results in better performance when speed is important - for example, in the classroom situation. However, because we did not separately record the time children thought about a TT-A item and the time needed for the motor response on that item, we do not know whether we are dealing with a developmental difference in thinking speed or in motor speed. This warrants further research in this area of language comprehension whereby emphasis can be placed on separating the effect of thinking time from response speed.

With respect to the influence of parental level of education on language comprehension, we found that children of highly educated parents had an advantage over children from a low/middle education background with respect to accuracy on the ABC-L. No similar effect was found for the TT-A. The results thus suggest that children with highly educated parents perform more accurately on one of the complex comprehension tasks used in this study. A possible explanation for this distinction can be found in the content of the items. The amount of imagination and abstraction needed to respond correctly appears to be larger for the ABC-L than for the TT-A. After all, the TT-A response options can be easily considered given that the tokens are laid out in front of the participant. Different response strategies can be prepared and tested as the TT-A item is presented, whereas
$\mathrm{ABC}-\mathrm{L}$ items and their possible responses can only be stored in working memory. Highly educated parents could be expected to use more abstract language in daily communication and thus train their children to respond orally in this way. In other words, children from highly educated families may have an advantage over children from lower educated families in understanding complex language that requires an oral response.

The results of this study have to be interpreted in the light of several limitations. First, although the sample size was large, and care was taken to include children from various socioeconomic backgrounds, relatively few children whose parents had low levels of education could be included in the study. This reduced the extent to which the findings can be generalized to the whole population. Second, the number of times an item was repeated was not recorded during test administration. Because of this, we do not know whether slow performance was caused by problems with storing the information (which would be reflected in numerous requests to repeat the item) or by actual language comprehension problems (which would be reflected in no requests for repetition). Future research should separate these issues by recording the number of repetitions per item and measuring the time that passes between these repetitions. Third, although levels of short-term memory were controlled for, working-memory abilities were not. Working memory may be of more importance in understanding the ABC-L items than is short-term memory because of the previously described requirement for imagination and abstraction. Future research should include both types of memory and control for their influence in the comprehension of complex language. Fourth, crosssectional samples are obviously less suitable for developmental research than longitudinal samples. This underscores the need for large-scale longitudinal investigations in complex language comprehension and other aspects of cognitive development.

In conclusion, complex language comprehension is a higher order cognitive function that continues to develop until early adolescence. The findings of this study have several implications for research and clinical practice. First, the language comprehension batteries such as those used in this study appear to be promising measures for investigating the development of this function. The results of the present study can potentially be used as preliminary normative data for the use of these tests. In addition to investigating large groups of healthy children and adolescents according to a longitudinal design, future research should investigate children with developmental disabilities. Children with 
attention deficit hyperactivity disorder and with pervasive development disorder are especially relevant in this respect because these children have executive problems as well as deficits in understanding certain aspects of complex language (Bruce, Thernlund, \& Nettelbladt, 2006; Camarata \& Gibson, 1999; Cohen et al., 2000; Geurts et al., 2004; Lorch, Milich, \& Sanchez, 1998; Mathers, 2006; Pennington \& Ozonoff, 1996; Purvis \& Tannock, 1997; Tirosh \& Cohen, 1998; Walker et al., 2004). This kind of research could eventually lead to not only a better understanding of these disorders but also better management of these children and more optimal didactic approaches. Lastly, the present findings may have implications for educational practice as they suggest that (a) the complexity of a verbal instruction provided by a teacher, and (b) the amount of time provided to understand this instruction may determine the comprehension of the pupil and that this may even be the case for older elementary school children and young adolescents enrolled in secondary school.

Original manuscript received 5 December 2006
Revised manuscript accepted 13 June 2007
First published online 7 August 2007

\section{REFERENCES}

Anderson, P. (2002). Assessment and development of executive function (EF) during childhood. Child Neuropsychology, 8, 71-82.

Anderson, V., Anderson, P., Northam, E., Jacobs, R., \& Catroppa, C. (2001). Development of executive functions through late childhood and adolescence in an Australian sample. Developmental Neuropsychology, 20, 385-406.

Baddeley, A. (2003). Working memory and language: An overview. Journal of Communication Disorders, 36, 189-208.

Bashir, A. S., \& Scavuzzo, A. (1992). Children with language disorders: Natural history and academic success. Journal of Learning Disabilities, 25, 53-65.

Bates, E., Thal, D., Finlay, B., \& Clancy, B. (2003). Early language development and its neural correlates. In S. J. Segalowitz \& I. Rapin (Eds.), Handbook of neuropsychology (pp. 525-592). Amsterdam: Elsevier Science.

Bauer, D. J., Goldfield, B. A., \& Reznick, J. S. (2002). Alternative approaches to analysing individual differences in the rate of early vocabulary development. Applied Psycholinguistics, 23, 313-336.

Blakemore, S.-J., \& Choudhury, S. (2006). Development of the adolescent brain: Implications for executive function and social cognition. Journal of Child Psychology and Psychiatry, 47, 296-312.

Blomert, L. (2002). Stand van zaken dyslexie [State of affairs dyslexia]. In Dyslexie; Naar een vergoedingsregeling [Dyslexia; Towards a reimbursement of expenses] (Rapport 03-144, pp. 28-139). Amstelveen, The Netherlands: College voor Zorgverzekeringen.
Booth, J. R., MacWhinney, B., \& Harasaki, Y. (2000). Developmental differences in visual and auditory processing of complex sentences. Child Development, 71, 981-1003.

Brocki, K. C., \& Bohlin, G. (2004). Executive functions in children aged 6 to 13: A dimensional and developmental study. Developmental Neuropsychology, 26, 571-593.

Bruce, B., Thernlund, G., \& Nettelbladt, U. (2006). ADHD and language impairment: A study of the parent questionnaire FTF (five to fifteen). European Child and Adolescent Psychiatry, 15, 52-60.

Camarata, C. M., \& Gibson, T. (1999). Pragmatic language deficits in attention-deficit hyperactivity disorder (ADHD). Mental Retardation and Developmental Disabilities Research Review, 5, 207-214.

Carpenter, P. A., Miyake, A., \& Just, M. A. (1994). Working memory constraints in comprehension. Evidence from individual differences, aphasia, and aging. In M. A. Gernsbacher (Ed.), Handbook of psycholinguistics (pp. 1075-1122). San Diego, CA: Academic Press.

Casey, B. J., Tottenham, N., Liston, C., \& Durston, S. (2005). Imaging the developing brain: What have we learned about cognitive development? Trends in Cognitive Sciences, 9, 104-110.

Christensen, A.-L. (1993). Luria's neuropsychological investigation text. Risskov, Denmark: P. J. Schmidts Bogtrykkeri, Vojens

Clifton, C., Jr., \& Duffy, S. A. (2001). Sentence and text comprehension: Roles of linguistic structure. Annual Review of Psychology, 52, 167-196.

Cohen, N. J., Vallance, D. D., Barwick, M., Im, N., Menna, R., Horodezky, N. B., et al. (2000). The interface between ADHD and language impairment: An examination of language, achievement, and cognitive processing. Journal of Child Psychology and Psychiatry, 41, 353-362.

Cook, M., Murdoch, B., Cahill, L., \& Whelan, B.-M. (2004). Higher-level language deficits resulting from primary cerebellar lesions. Aphasiology, 18, 771-784.

Crone, E. A., Bunge, S. A., van der Molen, M. W., \& Ridderinkhof, K. R. (2006). Switching between tasks and responses: A developmental study. Developmental Science, 9, 278-287.

De Bellis, M. D., Keshevan, M. S., Beers, S. R., Hall, J., Frustaci, K., Maselehdan, A., et al. (2001). Sex differences in brain maturation during childhood and adolescence. Cerebral Cortex, 11, 552-557.

De Bruyn, E. E. J., Van der Steene, G., Van Haasen, P. P., Coetsier, P., Pijl, Y. J., Spoelders-Claes, R., et al. (1986). Wechsler Intelligence Scale for ChildrenRevised (WISC-R). Lisse, The Netherlands: Swets \& Zeitlinger.

Deevy, P., \& Leonard, L. B. (2004). The comprehension of wh-questions in children with specific language impairment. Journal of Speech, Language and Hearing Research, 47, 802-815.

Dennis, M., \& Barnes, M. A. (1990). Knowing the meaning, getting the point, bridging the gap, and carrying the message: Aspects of discourse following closed head injury in childhood and adolescence. Brain and Language, 39, 428-446.

De Renzi, E., \& Faglioni, P. (1978). Normative data and screening power of a shortened version of the Token Test. Cortex, 14, 41-49. 
Dick, F., Wulfeck, B., Krupa-Kwiatkowski, M., \& Bates, E. (2004). The development of complex sentence interpretation in typically developing children compared with children with specific language impairments or early unilateral focal lesions. Developmental Science, 7, 360-377.

Directoraat-Generaal voor de Arbeidsvoorziening. (1989). Handleiding voor de functieanalyse [Function analysis manual]. Den Haag, The Netherlands: SDU Uitgeverij.

DiSimoni, F. (1978). Token Test for Children (TTFC). Austin, TX: PRO-ED.

Dodd, B., Holm, A., Hua, Z., \& Crosbie, S. (2003). Phonological development: A normative study of BritishEnglish speaking children. Clinical Linguistics and Phonetics, 17, 617-643.

Dollaghan, C. A., Campbell, T. F., Paradise, J. L., Feldman, H. M., Janosky, J. F., Pitcairn, D. N., et al. (1999). Maternal education and measures of early speech and language. Journal of Speech, Language and Hearing Research, 42, 1432-1443.

Edwards, S., Fletcher, P., Garman, M., Hughes, A., Letts, C., \& Sinka, I. (1997). The Reynell Developmental Language Scales III: The University of Reading Edition. Windsor, UK: NFER-Nelson.

Eslinger, P. J., Flaherty-Craig, C. V., \& Benton, A. L. (2004). Developmental outcomes after early prefrontal cortex damage. Brain and Cognition, 55, 84-103.

Fuster, J. M. (2002). Frontal lobe and cognitive development. Journal of Neurocytology, 31, 375-385.

Geurts, H. M., Verté, S., Oosterlaan, J., Roeyers, H., Hartman, C. A., Mulder, E. J., et al. (2004). Can the Children's Communication Checklist differentiate between children with autism, children with ADHD, and normal controls? Journal of Child Psychology and Psychiatry, 45, 1437-1453.

Gogtay, N., Giedd, J. N., Lusk, L., Hayaski, K. M., Greenstein, D., Vaituzis, A. C., et al. (2004). Dynamic mapping of human cortical development during childhood through early adulthood. Proceedings of the National Academy of the Sciences, 101, 8174-8179.

Hahne, A., Eckstein, K., \& Friederici, A. D. (2004). Brain signatures of syntactic and semantic processes during children's language development. Journal of Cognitive Neuroscience, 16, 1302-1318.

Hale, S. (1990). A global developmental trend in cognitive processing speed. Child Development, 61, 653-663.

Helland, T., \& Asbjornsen, A. (2004). Digit span in dyslexia: Variations according to language comprehension and mathematics skills. Journal of Clinical and Experimental Neuropsychology, 26, 31-42.

Hoff, E. (2003). The specificity of environmental influence: Socioeconomic status affects early vocabulary development via maternal speech. Child Development, $74,1368-1378$.

Holm, O., Greaker, E., \& Stroemberg, A. (2002). Experiences of longing in Norwegian and Swedish 4- and 5-year-old children. Journal of Psychology, 136, 608-612.

Hurks, P. P., Vles, J. S., Hendriksen, J. G., Kalff, A. C., Feron, F. J., Kroes, M., et al. (2006). Semantic category fluency versus initial letter fluency over 60 seconds as a measure of automatic and controlled processing in healthy school-aged children. Journal of Clinical and Experimental Neuropsychology, 28, 684-695.
Jackson, A. P. (2003). The effects of family and neighbourhood characteristics on the behavioural and cognitive development of poor black children: A longitudinal study. American Journal of Community Psychology, 32, 175-186.

Johnson, M. H, \& Munakata, Y. (2005). Processes of change in brain and cognitive development. Trends in Cognitive Sciences, 9, 152-158.

Just, M. A., \& Carpenter, P. A. (1992). A capacity theory of comprehension: Individual differences in working memory. Psychological Review, 99, 122-149.

Kail, R. (1991). Developmental change in speed of processing during childhood and adolescence. Psychological Bulletin, 109, 490-501.

Kail, R. (1996). Nature and consequences of developmental change in speed of processing. Swiss Journal of Psychology, 55, 133-138.

Kail, R. (2000). Speed of information processing: Developmental change and links to intelligence. Journal of School Psychology, 38, 51-61.

Kalff, A. C., De Sonneville, L. M., Hurks, P. P., Hendriksen, J. G., Kroes, M., Feron, F. J., et al. (2005). Speed, speed variability, and accuracy of information processing in 5 to 6-year-old children at risk of ADHD. Journal of the International Neuropsychological Society, 11, 173-183.

Kalff, A. C., Kroes, M., Vles, J. S. H., Bosma, H., Feron, F. J. M., Hendriksen, J. G. M., et al. (2001a). Factors affecting the relation between parental education as well as occupation and problem behavior in Dutch 5- to 6-year-old children. Social Psychiatry and Psychiatric Epidemiology, 36, 324-331.

Kalff, A. C., Kroes, M., Vles, J. S. H., Hendriksen, J. G. M., Feron, F. J. M., Steyaert, J., et al. (2001b). Neighborhood-level and individual-level SES effects on child problem behavior: A multilevel analysis. Journal of Epidemiology and Community Health, 55, 246-250.

Klingberg, T., Vaidya, C. J., Gabrieli, J. D. E., Moseley, M. E., \& Hedehus, M. (1999). Myelination and organization of the frontal white matter in children: A diffusion tensor MRI study. NeuroReport, 10, 2817-2821.

Korkman, M., Kirk, U., \& Kemp, S. (1998). NEPSY: A developmental neuropsychological assessment. Manual. San Antonio, TX: The Psychological Corporation.

Kroes, M., Kalff, A. C., Kessels, A. G., Steyaert, J., Feron, F. J., van Someren, A. J., et al. (2001). Child psychiatric diagnoses in a population of Dutch schoolchildren aged 6 to 8 years. Journal of the American Academy of Child and Adolescent Psychiatry, 40, 1401-1409.

Landry, S. H., Smith, K. E., \& Swank, P. R. (2002). Environmental effects on language development in normal and high-risk child populations. Seminars in Pediatric Neurology, 9, 192-200.

Lezak, M. D., Howieson, D. B., \& Loring, D. W. (2004). Neuropsychological assessment (4th ed.). New York: Oxford University Press.

Lorch, E. P., Milich, R., \& Sanchez, R. P. (1998). Story comprehension in children with ADHD. Clinical Child and Family Psychology Review, 1, 163-178.

Luciana, M., Conklin, H. M., Hooper, C. J., \& Yarger, R. S. (2005). The development of nonverbal working memory and executive control processes in adolescents. Child Development, 76, 697-712. 
Luria, A. R. (1966). Higher cortical functions in man. New York: Basic Books.

Luria, A. R. (1980). Higher cortical functions in man. New York: Basic Books.

Mackner, L. M., Black, M. M., \& Starr, R. H., Jr. (2003). Cognitive development of children in poverty with failure to thrive: A prospective study through age 6. Journal of Child Psychology and Psychiatry, 44, 743-751.

Marton, K., \& Schwartz, R. G. (2003). Working memory capacity and language processes in children with specific language impairment. Journal of Speech, Language and Hearing Research, 46, 1138-1153.

Mathers, M. E. (2006). Aspects of language in children with ADHD: Applying functional analyses to explore language use. Journal of Attention Disorders, 9, 523-533.

McNeil, M. M., \& Prescott, T. E. (1978). Revised Token Test (RTT). Austin, TX: PRO-ED.

Meijs, C. J. C., Hurks, P. P. M., Wassenberg, R., Feron, F. J. M., \& Jolles, J. (2007). The influence of presentation modality on performance on a verbal learning test in healthy children aged 5-16 years. Manuscript in preparation.

Montgomery, J. W. (2003). Working memory and comprehension in children with specific language impairment: What we know so far. Journal of Communication Disorders, 36, 221-231.

Nigg, J. T. (2000). On inhibition/disinhibition in developmental psychopathology: Views from cognitive and personality psychology and a working inhibition taxonomy. Psychological Bulletin, 126, 220-246.

Paus, T. (2005). Mapping brain maturation and cognitive development during adolescence. Trends in Cognitive Sciences, 9, 60-67.

Pennington, B. F., \& Ozonoff, S. (1996). Executive functions and developmental disabilities. Journal of Child Psychology, 37, 51-87.

Purvis, K. L., \& Tannock, R. (1997). Language abilities in children with attention deficit hyperactivity disorder, reading disabilities, and normal controls. Journal of Abnormal Child Psychology, 25, 133-144.

Quay, L. C., \& Blaney, R. L. (1992). Verbal communication, nonverbal communication, and private speech in lower and middle socioeconomic status preschool children. Journal of Genetic Psychology, 153, 129-138.

Roulstone, S., Loader, S., Northstone, K., \& Beveridge, M. (2002). The speech and language of children aged 25 months: Descriptive data from the Avon Longitudinal Study of Parents and Children. Early Child Development and Care, 172, 259-268.

Semel, E., Wiig, E. H., \& Secord, W. A. (1995). Clinical Evaluation of Language Fundamentals-third edition
(CELF-3). San Antonio, TX: The Psychological Corporation.

Shaw, P., Greenstein, D., Lerch, J., Clasen, L., Lenroot, R., Gogtay, N., et al. (2006). Intellectual ability and cortical development in children and adolescents. Nature, 440, 676-679.

Steinberg, L. (2005). Cognitive and affective development in adolescence. Trends in Cognitive Sciences, 9, 69-74.

Stuss, D. T. (1992). Biological and psychological development of executive functions. Brain and Cognition, $20,8-23$.

Tirosh, E., \& Cohen, A. (1998). Language deficit with attention-deficit disorder: A prevalent comorbidity. Journal of Child Neurology, 13, 493-497.

Travis, F. (1998). Cortical and cognitive development in 4 th, 8 th and 12 th grade students. The contribution of speed of processing and executive functioning to cognitive development. Biological Psychology, 48, 37-56.

Tse, S. K., Kwon, S. M., Chan, C., \& Li, H. (2002). Sex differences in syntactic development: Evidence for Cantonese-speaking preschoolers in Hong Kong. International Journal of Behavioral Development, 26, 509-517.

Van der Elst, W., van Boxtel, M. P., van Breukelen, G. J., \& Jolles, J. (2006). The Letter Digit Substitution Test: Normative data for 1,858 healthy participants aged 24-81 from the Maastricht Aging Study (MAAS): Influence of age, education, and sex. Journal of Clinical and Experimental Neuropsychology, 28, 998-1009.

Van Eldik, M. C. M., Schlichting, J. E. P. T., LutjeSpelberg, H. C., Van der Meulen, B. F., \& Van der Meulen, S. (1995). Reynell Test voor Taalbegrip, handleiding [Reynell Test for Language Comprehension, manual]. Nijmegen, The Netherlands: Berkhout.

Walker, D. R., Thompson, A., Zwaigenbaum, L., Goldberg, J., Bryson, S. E., Mahoney, W. J., et al. (2004). Specifying PDD-NOS: A comparison of PDD-NOS, Asperger syndrome, and autism. Journal of the American Academy of Child and Adolescent Psychiatry, 43, 172-180.

Wassenberg, R., Hurks, P. P. M., Hendriksen, J. G. M., Kalff, A. C., Slaats-Willemse, D. I. E., Feron, F. J. M., et al. (2007). Comprehension of logical grammatical structures in school aged children. Manuscript submitted for publication.

Wechsler, D. (1974). Wechsler Intelligence Scale for Children-Revised. Manual. San Antonio, TX: The Psychological Corporation. 